\title{
Review for the Curriculum and License Exam of Physical Therapists in the United States
}

\author{
Chi-Whan Choi', Yeon-Gyu Jeong ${ }^{2}$ \\ 'Department of Rehabilitation Medicine, Seoul National University Hospital; ²Department of Physical Therapy, Yeoju Institute of Technology, Yeoju \\ Korea
}

Purpose: This study was conducted to review the curriculum and license examination of physical therapists in the United States.

Methods: The doctor of physical therapy (DPT) curriculum was evaluated by a review Course Work Tool version 6 (CWT6) data and current physical therapy licensure examination (National Physical Therapy Exam, NPTE) category in the United States.

Results: The results indicated that they were required to meet the doctor of physical therapist degree based on 'Guide to Physical Therapist Practice' of American Physical Therapy Association (APTA). This includes general education in the areas of communications and humanities, physical science, biological science, social and behavioral science, and mathematics. A minimum of one course must be completed successfully in each area of general education. Moreover, there should be at least 68 didactic credits of professional education and 22 clinical education credits, which is a minimum of two full-time clinical internships with no less than 1050 hours in total, which were supervised by a physical therapist. Regarding the physical therapy licensure examination, National Physical Therapy Exam (NPTE, 2016) consisted of a physical therapy examination (26.5\%), evaluation, differential diagnosis, baseline of prognosis (32.5\%), intervention (28.5\%), protection, responsibility, and research (6.5\%) based on the 'Guide to Physical Therapist Practice.'

Conclusion: Based on the study results provided above, it is considered a standard to meet domestic reality as the Guide to Physical Therapist Practice of APTA for South Korean physical therapists.

Keywords: Course work tool version 6, National physical therapy exam, Guide to physical therapist practice

\section{서 론}

노령 인구와 만성질환자가 증가함에 따라 의료체계도 변화하고 있 다. 기존 급성·만성 환자의 건강 관리뿐 아니라 질병의 예방과 자가 관리(self-management)를 강조하는 병원중심패턴에서 환자의 가정, 사회, 환경 요인을 강조하는 지역중심패턴으로 달라지고 있다.' 또한 건강에 대한 관심과 건강하게 살고자 하는 욕구가 증가하고 있으며, 이에 따라 건강 관리 전문가에 대한 사회적 기대와 수요 역시 늘어나 고 있는 추세이다.2 전문 직업은 특수한 지식과 기술을 토대로 광범위 한 기능적 자율성을 갖고 수행된 과업의 성과에 따라 보수를 받는 직 업을 말하는데, 물리치료사는 대표적인 건강 전문직에 속한다. ${ }^{2}$

1945년 물리치료가 한국에 도입된 이후 최근에 이르기까지 물리 치료는 많은 발전을 거듭해왔다. 1950년 발발한 한국전쟁으로 인한 부상자들을 관리하기 위해 정양원(부산 동래 소재)에 최초로 물리치
료 교육제도가 만들어졌으며, 1963년에는 정규 교육기관인 수도의과 대학 병설 의학기술 초급대학(고려대학교 보건대학 물리치료학과), 1988년에는 최초의 4 년제 물리치료학과가 대구대학교에 개설 되었 다. 2018 년 국내 물리치료학과 개설 현황은 4년제 대학 45개교, 3 년제 대학 39 개교에 이르며 졸업 정원은 4,199 명에 달한다. 또한 2018년 현 재 39개 대학에 물리치료 관련 대학원 과정(석사/박사)이 개설되어 있다.3한국의 물리치료는 50 여년의 역사를 거치며 사회의 발전, 국민 보건향상에 따른 수준 높은 요구도에 따라 교육과정, 물리치료 업무 등에서 더욱 다양화되고 전문화 되었다. 과거에는 의사만이 질병 진 단과 치료를 담당하는 보건의료 전문 인력으로 인식되었으며, 의료 기사 등 다른 보건의료 담당자는 단지 의사의 보조자로 간주되어온 것이 사실이다. 그러나 현대사회에서는 의료업이 전문화하면서 의료 기사 등은 의사를 보완 대체하는 각종 보건의료 영역을 담당하게 되 었다. 이에 따라 양질의 의료서비스를 제공하기 위하여 의료기사의
Received Jul 1, 2019 Revised Aug 24, 2019

Accepted Aug 29, 2019

Corresponding author Yeon-Gyu Jeong

E-mail assa-yk@hanmail.net
Copylight (C)2019 The Korean Society of Physical Therapy

This is an Open Access article distribute under the terms of the Creative Commons Attribution Non-commercial License (Http:// creativecommons.org/license/by-nc/4.O.) which permits unrestricted non-commercial use, distribution, and reproduction in any medium, provided the original work is properly cited. 
역할과 기능이 더욱 강조되고 있는 상황이다. ${ }^{4}$ 한국물리치료는 세계 물리치료연맹(WCPT, world confederation for physical therapy)이 요구 하는 권장 사항에 따라 정책을 추진하고 있다. ${ }^{4}$ 일반적으로 물리치료 는 정형외과, 신경외과, 재활의학과 영역의 환자만을 치료하는 것으 로 이해하는 경우가 많지만 소아과, 산부인과, 흥부외과, 치과 등 의료 분야 전반에 포괄적으로 적용되고 있다. 질환에 따른 분류에서도 근 골격계 물리치료, 신경손상 물리치료, 소아 물리치료, 흥부 물리치료, 산부인과 물리치료, 스포츠 물리치료 등 전문화 및 세분화되어 가는 추세이다. ${ }^{4}$

물리치료사의 역할이 점차적으로 중요해지고 전문화되고 있음에 도 불구하고 국내 대학 과정의 물리치료 교육은 3 년제와 4 년제로 이 원화되어 교양교육 및 전공교육 이수의 폭이 큰 차이가 있고, 물리치 료 교육의 전문성을 확보하고 높은 질의 물리치료사 양성을 위해서 는 교육과정의 연구와 개발이 꼭 필요한 실정이다. ${ }^{1}$

이에 본 연구의 목적은 다변화하는 현실에서 건강전문가인 물리치 료사에게 요구되는 역량에 대한 이해의 폭을 넓히는데 도움이 되고 자 최근에 교과과정을 개선한 미국 물리치료 교육과정과 면허시험 을 분석해보려고한다.

\section{연구 방법}

\section{1. 자료수집}

참고가 될 수 있는 국내 학술지 전문 데이터베이스(RISS, KISS, DBpia, 구글학술, 국회도서관)에서 국내외 물리치료사 교과과정, 국가고시, 면허시험을 검색하여 자료를 수집하였고 미국의 물리치료 교육과정 에 대한 연구 및 현재 시행중인 미국면허시험에 대한 관련자료는 해 외 학술지 전문 데이터베이스(Ovid MEDLINE, CINAHL (EBSCO), Web of Science, and PEDro)을 조사하여 문헌고찰을 실시하였다. 분석 대상 자료는 2001년부터 2018년 12월까지 학술지에 발표된 논문과 관 련정보를 활용하여 검색하였다.

\section{2. 자료추출}

수집된 자료 중에서 국내 물리치료의 변화와 현재 현황에 대한 내용 을 포함시켰고 미국의 물리치료 임상 박사(doctor of physical therapy, DPT) 전문교육 프로그램에 대해 조사하였다. 교육과정에 포함되는 내용은 FSBPT (federation of state boards of physical therapy)에서 제공 하는 CWT6 (coursework tool 6 for foreign educated physical therapists)을 통해 확인하였다. 수집된 자료 중에서 미국물리치료사 면허시험은 물 리치료 검진, 평가, 감별진단, 예후의 기초, 중재, 기기 및 물리적 인자 치료, 안전과 보호, 책임, 연구의 총 5 개 과목에 대해 자료를 조사하였 고 각각의 과목에서 실제 출제 되는 문제 경향에 대해 확인하였다.

\section{3. 연구 제한점}

미국 물리치료 교육과정과 면허시험의 특성을 검토하는 것을 범위로 하였으나 연구의 범위와 내용에 실증적 한계가 있음을 밝혀둔다.

\section{결 과}

\section{1. 미국 물리치료 교육과정}

미국의 경우 최근 대학에 해당하는 과정을 이수하고 국가고시에 합 격하여 물리치료사가 되는 시스템이 거의 사라지고 있다. 최근에는 대학 졸업 시까지 일정 과목을 이수하고 석사 과정(MPT, master of physical therapy)과 임상 박사 과정(DPT, doctor of physical therapy)을 수료한 이들에 한하여 시험을 실시해 물리치료를 행할 수 있도록 하 고 있다. 물리치료 임상 박사(doctor of physical therapy, DPT)란 전문교 육 프로그램 또는 전문심화교육 프로그램을 이수했을 때 수여되는 학부과정 후 학위이다. ${ }^{5}$ DPT에는 'professional', 'transition'과 'advanced clinical science' 등이 있는데 이들은 모두 전문적인 '임상 박사 학위로 서 $\mathrm{PhD}$ (doctor of philosophy)와 같은 연구 과정과는 다르다. 'professional' DPT는 학부 졸업 이후 과정으로 물리치료사 전문교육프로그 램을 성공적으로 마치면 받는 학위이다. 타 전공의 일반 학부를 마치 고 선수 과목을 이수한 경우 입학이 가능하며 3년 과정을 이수하면 면허를 취득할 수 있다. ${ }^{5}$ Post-professional DPT 'transition'은 이전 방식 의 물리치료 교육 후 면허를 취득한 사람들에게 제공되는 프로그램 으로 1년 동안 주어진 학점을 이수해야만 한다. 'advanced clinical science' DPT는 post-professional DPT' transition'을 이수한 경우에 수여되 는 학위 중 하나이다. 이들 과정은 대부분 전문적인 임상 연수 과정 을 포함하고 있고, 임상 연수 과정을 마치면 학위를 수여하고 미국 물 리치료 면허시험(NPTE) 자격이 주어진다. 미국 물리치료사협회(the american physical therapy association, APTA)는 1990년 후반부터 물리 치료 임상 박사(DPT) 과정을 개설하여 DPT학위 취득을 장려하고 있 으며 '비전 2020'을 통해 미국 내 모든 물리치료사가 2020년까지 DPT 를 취득하도록 추진하고 있다. 또한 공인 물리치료 교육 위원회(commission on accreditation in physical therapy education)에서는 2002년 이 후 학부 과정을 더 이상 인가하지 않고 있으며 임상 박사 과정을 적극 적으로 인가하고 있다. ${ }^{3}$

$\mathrm{APTA}$ 에서는 DPT과정이 필요한 이론적 근거를 다음과 같이 제시 하고 있다. 첫째, 'guide to physical therapist practice'에서는 물리치료사 가 환자에게 광범위하고 심도 있는 수준의 물리치료를 제공해야 한 다고 제시하고 있는데, 이는 현재 행해지고 있는 교육 프로그램에서 는 쉽게 얻기 어렵기 때문이다. 둘째, 개업한 보건관련 전문가들에 대한 사회적 기대가 'guide to physical therapist practice'에서 언급하는 임상 박사와 일치하기 때문이다. 셋째, 환자에게 근거중심치료의 관 
점에 맞는 임상치료기술을 습득하여 적용하여야만 적당한 치료비 를 청구할 수 있는데, 이는 개업을 한 물리치료사가 수의사, 약사, 치 과의사와 마찬가지로 임상 박사 학위를 가지고 있어야 한다는 요구 가 절대적이기 때문이다. ${ }^{3}$ 마지막으로, 현재 실시되고 있는 많은 석사 학위 프로그램이 이미 임상 박사 학위의 요구를 충족시켰기 때문이 다.3이처럼 미국에서는 물리치료사의 질적인 수준을 높이기 위한 학 제의 변화가 활발히 일어나고 있다.

DPT과정을 마친 후 면허시험을 통해 자격을 얻는 경우 외에, 미국 이 아닌 다른 나라에서 물리치료를 전공한 외국인인 경우에도 일정
한 자격을 갖추면 면허시험에 응시할 수 있도록 하고 있다. 주마다 자 격조건이 다르지만 대부분의 주에서는 석사학위에 준하는 조건을 요구하고 있다. 최근에는 비전 2020에 맞추어, 시험 자격을 검증하는 기관인 FSBPT (federation of state boards of physical therapy)는 CWT6 (coursework tool 6 for foreign educated physical therapists)에서 최소 전 공 학점 68학점과 임상실습 22학점(1050시간)을 포함한 180학점 이상 의 교육 이수를 요구하고 있다. 또한 2018년부터는 시험에 응시할 경 우 토플 점수를 요구하는 등 그 기준을 강화하고 있고 면허시험에 합 격한 경우에도 미국 내에서 일하는 취업비자를 얻기 위한 Typel 심사

Table 1. General education

\begin{tabular}{|c|c|}
\hline Category & Subject \\
\hline \multirow[t]{11}{*}{ Communication and Humanities: One course minimum from the category } & English Language \\
\hline & English Composition \\
\hline & Speech or Oral Communication \\
\hline & Foreign Language \\
\hline & Native Language \\
\hline & Composition of Research Writing \\
\hline & Literature \\
\hline & Visual Arts \\
\hline & Performing Arts \\
\hline & Philosophy \\
\hline & Ethics \\
\hline \multirow[t]{4}{*}{ Physical Science: One course in chemistry (with laboratory) and one course in physics (with laboratory) are required.* } & Chemistry (with laboratory)* \\
\hline & Physics (with laboratory)* \\
\hline & Geology \\
\hline & Astronomy \\
\hline \multicolumn{2}{|l|}{ Biological Science: (General - not core to PT) One course minimum } \\
\hline & Biology \\
\hline & Anatomy \\
\hline & Physiology \\
\hline & Zoology \\
\hline & Kinesiology \\
\hline & Neuroscience \\
\hline & History \\
\hline \multirow[t]{7}{*}{ Social and Behavioral Science: Two courses minimum from the category } & Geography \\
\hline & Sociology \\
\hline & Economics \\
\hline & Religion \\
\hline & Political Science \\
\hline & Psychology* \\
\hline & Anthropology \\
\hline \multirow[t]{7}{*}{ Mathematics: One course minimum from the category } & Statistics \\
\hline & Algebra \\
\hline & Pre-Calculus \\
\hline & Calculus \\
\hline & Trigonometry \\
\hline & Geometry \\
\hline & Computer Studies \\
\hline
\end{tabular}


Table 2. Professional education

\begin{tabular}{|c|c|}
\hline Category & Subject \\
\hline Basic Health Science: & Human Anatomy /core to PT \\
\hline \multirow[t]{11}{*}{ Must include but not limited to areas } & Human Physiology / core to PT \\
\hline & $\begin{array}{l}\text { Neuroscience (Neuroanatomy/ } \\
\text { Neurophysiology) }\end{array}$ \\
\hline & $\begin{array}{l}\text { Kinesiology, Functional Anatomy, } \\
\text { or Biomechanics }\end{array}$ \\
\hline & Pathology \\
\hline & Pharmacology \\
\hline & Genetics \\
\hline & Histology \\
\hline & Nutrition \\
\hline & Exercise Science \\
\hline & $\begin{array}{l}\text { Psychosocial aspects of health, } \\
\text { disability, physical therapy }\end{array}$ \\
\hline & Diagnostic imaging \\
\hline Medical Science: & Cardiovascular (including Lymphatic) \\
\hline \multirow[t]{12}{*}{ Must include but not limited to areas } & Respiratory \\
\hline & Endocrine\& Metabolic \\
\hline & Renal, Genitourinary \\
\hline & Immune \\
\hline & Integumentary \\
\hline & Musculoskeletal \\
\hline & Neurologic \\
\hline & System Interactions \\
\hline & Differential Diagnosis \\
\hline & $\begin{array}{l}\text { Medical, Surgical Conditions } \\
\text { across the life span }\end{array}$ \\
\hline & Pediatrics \\
\hline & Geriatrics \\
\hline Examination: & History \\
\hline \multirow[t]{18}{*}{ Must include but not limited to Areas } & Screening \\
\hline & Systems Review \\
\hline & $\begin{array}{l}\text { Physical Exams, Tests, } \\
\text { Measures Selection }\end{array}$ \\
\hline & Tests and Measures Administration: \\
\hline & a. Aerobic capacity/Endurance \\
\hline & b. Anthropometric characteristics \\
\hline & c. Mental Functions \\
\hline & d. Assistive, adaptive devices \\
\hline & $\begin{array}{l}\text { e. Community, work (job, school, or } \\
\text { play) reintegration }\end{array}$ \\
\hline & f. Cranial Nerve Integrity \\
\hline & g. Peripheral Nerve Integrity \\
\hline & $\begin{array}{l}\text { h. Environmental, home, work } \\
\text { barriers }\end{array}$ \\
\hline & i. Ergonomics, body mechanics \\
\hline & j. Gait \\
\hline & k. Integumentary integrity \\
\hline & I. Joint integrity and mobility \\
\hline & m. Mobility (excluding gait) \\
\hline & n. Motor function \\
\hline
\end{tabular}

(Continued to the next page)

\begin{tabular}{|c|c|}
\hline Category & Subject \\
\hline & o. Muscle performance \\
\hline & $\begin{array}{l}\text { p. Neuromotor development, } \\
\text { sensory processing }\end{array}$ \\
\hline & q. Pain \\
\hline & r. Posture \\
\hline & s. Range of motion \\
\hline & t. Reflex integrity \\
\hline & u. Self-care, home management \\
\hline & v. Sensory integrity \\
\hline & $\begin{array}{l}\text { w. Ventilation, respiration or gas } \\
\text { exchange }\end{array}$ \\
\hline Evaluation: & Data Analysis and Evaluation \\
\hline \multirow[t]{4}{*}{ Must include but not limited to areas } & Patient Problem Identification \\
\hline & Findings that Warrant Referral \\
\hline & Prognosis and Goal Formulation \\
\hline & Plan of Care Development \\
\hline Plan of Care Implementation: & Interventions \\
\hline \multirow[t]{18}{*}{ Must include but not limited to areas } & a. Airway clearance techniques \\
\hline & b. Integumentary Repair \& Protection \\
\hline & c. Wound Debridement \\
\hline & d. Electrotherapy \\
\hline & e. Physical Agents \\
\hline & f. Mechanical Agents \\
\hline & $\begin{array}{l}\text { g. Community, Work Functional } \\
\text { Training }\end{array}$ \\
\hline & $\begin{array}{l}\text { h. Self-Care, Home Management } \\
\text { Function Training }\end{array}$ \\
\hline & $\begin{array}{l}\text { i. Manual therapy techniques } \\
\text { (including joint and soft tissue } \\
\text { mobilization and massage) }\end{array}$ \\
\hline & j. Patient/Client Education \\
\hline & $\begin{array}{l}\text { k. Prescription, application, and as } \\
\text { appropriate, fabrication of assistive, } \\
\text { adaptive, orthotic, protective, } \\
\text { supportive, and prosthetic devices } \\
\text { and equipment }\end{array}$ \\
\hline & I. Therapeutic exercise \\
\hline & m. Mobility Training \\
\hline & Plan of Care Management \\
\hline & Supervision of Support Staff \\
\hline & Outcome Assessment \\
\hline & Discharge or Discontinuation \\
\hline & $\begin{array}{l}\text { Patient-related Emergency } \\
\text { Procedures }\end{array}$ \\
\hline \multicolumn{2}{|l|}{ Related Professional Coursework: } \\
\hline \multirow[t]{6}{*}{ Must include but not limited to areas } & Professional Roles and Behaviors \\
\hline & $\begin{array}{l}\text { Healthcare Systems, Administration, } \\
\text { and Management }\end{array}$ \\
\hline & Community Health \\
\hline & Health Promotion and Wellness \\
\hline & Clinical Decision Making \\
\hline & $\begin{array}{l}\text { Processes - Evidence-based Practice } \\
\text { and }\end{array}$ \\
\hline
\end{tabular}


는 DPT과정에 준하는 석사나 t-DPT 학위를 요구하며 210학점이상과 토플점수 89점 이상(스피킹: 26점 이상)을 요구하고 있다.CWT6에서 요 구하는 기초 과목은 전공과목은 다음과 같은데(Table 1, 2), 이를 통해 미국의 물리치료 교육과정이 어디에 중점을 두고 있는지 파악할 수 있 다. 기초과정으로 커뮤니케이션 및 인문학, 자연과학(실험을 포함한 물 리, 화학), 생물과학, 사회 및 행동 과학과 수학이 요구되고 전공과목으 로 기초보건과학, 의 과학에 더불어 검진, 평가, 치료 그리고 임상 실습 이 중점이 되며 'guide to physical therapist practice'에 기준을 두고 있다.

Table 2. Continued

\begin{tabular}{ll}
\hline Category & Subject \\
\hline Teaching and Learning & (including educational theory) \\
Documentation (all aspects of & patient/client management) \\
Communication \\
Legal and Regulatory Aspects \\
Federation of State Boards of \\
Physical Therapy \\
Ethical Aspects and values of Physical \\
Therapy Practice \\
Teamwork and Interprofessional \\
Collaboration \\
Cultural Competency \\
Consultation \\
Physical therapist-supervised \\
application of physical therapy \\
theory, examination, evaluation, \\
and intervention \\
22 credits required (1050Hours) \\
Clinical Education:
\end{tabular}

\section{2. 미국 물리치료사 면허시험}

최근 미국 물리치료사 면허시험(2016년)은 물리치료 검진(26.5\%), 평 가, 감별진단, 예후의 기초(32.5\%), 중재(28.5\%), 기기 및 물리적 인자치 료 $(6 \%)$, 안전과 보호, 책임, 연구(6.5\%) 총 5개 과목으로 구성되어 있다 (Table 3$)^{6}$

\section{1) 물리치료 검진(physical therapy examination)}

물리치료사는 치료적 중재를 위해 환자의 상태를 평가하는 물리치 료 검진(physical therapy examination)을 시행한다. 검진(examination) 은 '면밀히 조사하다'라는 의미이다. 미국 물리치료사 면허시험: NPTE (national physical therapy exam)에서는 물리치료사에게 익숙한 관절가동범위 검사, 도수근력 검사, 특수검사(special test), 피부 분절 및 근절 검사, 감각 검사, 균형 및 보행 검사, 발달 검사, 심폐지구력 검 사 등의 근.골격계 물리치료 검사, 신경계 물리치료 검사, 소아 물리 치료 검사, 흥부 물리치료 검사, 피부계 물리치료 검사에 대해 묻는다.

'검진(examination)'에는 환자 인터뷰(patient history \& systemic review)와 검사 및 측정이 포함된다. 의사의 이학적 검진(physical examination)과 물리치료사의 물리치료 검진(physical therapy examination) 의 차이는 병리(pathology)와 손상(impairment), 기능 제한(functional limitation) 중 어느 쪽에 중점을 두는가에 있다. 1965년 사회사업가인 사드 나지(Saad Nagi)는 건강 상태를 설명하기 위해 메디컬모델 'The Nagi Model' 을 도입했다. ' 이 모델은 병리, 손상, 기능제한, 불능의 네 가지 개념을 포함한다.

예를 들어 우체부로 일하던 남자가 체간과 하지의 점진적인 마비

Table 3. NPTE (national physical therapy exam) category

\begin{tabular}{|c|c|c|c|c|}
\hline Category & Subject & Number of questions & Percentage (\%) & Category (\%) \\
\hline \multirow[t]{4}{*}{ Physical Therapy Examination } & Musculoskeletal & 22 & 11.0 & 26.50 \\
\hline & Neuromuscular & 17 & 8.5 & \\
\hline & Cardiopulmonary & 10 & 5.0 & \\
\hline & Other system & 4 & 2.0 & \\
\hline Foundation for Evaluation, & Musculoskeletal & 18 & 9.0 & 32.50 \\
\hline \multirow[t]{3}{*}{ Differential Diagnosis\& Prognosis } & Neuromuscular & 15 & 7.5 & \\
\hline & Cardiopulmonary & 12 & 6.0 & \\
\hline & Other system & 20 & 10.0 & \\
\hline \multirow[t]{4}{*}{ Intervention } & Musculoskeletal & 21 & 10.5 & 28.50 \\
\hline & Neuromuscular & 18 & 9.0 & \\
\hline & Cardiopulmonary & 11 & 5.5 & \\
\hline & Other system & 7 & 3.5 & \\
\hline Equipment \& Device; & Equipment \& Device & 5 & 2.5 & 6.00 \\
\hline Therapeutic Modalities & Therapeutic Modalities & 7 & 3.5 & \\
\hline Safety and Protection & Safety and Protection & 5 & 2.5 & 6.50 \\
\hline Professional responsibilities & Professional responsibilities & 4 & 2.0 & \\
\hline Research & Research & 4 & 2.0 & \\
\hline
\end{tabular}


진행으로 의사로부터 흥추12번(T12) 척수 종양(spinal cord tumor) 진 단을 받았다. 현재 휠체어 이동 등의 일상생활에 도움이 필요하여 직 업활동을 지속할 수 없다면 병리(pathology)는 흥수12번 척수종양 (spinal cord tumor at T12), 불능(impairment)은 T12 이하의 운동기능 상 실, 기능제한(functional limitation)은 독립적인 이동(ambulation)이 불 가능, 장애(disability)는 '직업 활동을 유지할 수 없음이 된다. ${ }^{6}$ 병리(pathology)가 세포 수준의 문제로 발생한다면 불능(impairment)는 조직 (tissue), 기관(organ) 또는 신체계통(body system) 수준의 손실(loss)이나 이상(abnormality)을 의미하고 감정이나 심리적인 부분도 포함한다. 각 각의 병리(pathology)로 인해 불능(impairment)이 가능하지만 특별한 병리(pathology)가 없는 경우에도 불능(impairment)이 존재하는 경우 가 있다. 선천적인 기형을 제외하고 병리(pathology)가 없는 불능(impairment)를 우리는 보통 증후군(syndrome)으로 분류한다.

하지만 다양한 질환, 특히 근.골격계 통증의 경우 병리(pathology) 가 명확하지 않을 때가 있다. 물리치료 검진(physical therapy examination)은 이런 경우 이학적 검진(physical examination)을 보완할 수 있 다. 왜냐하면 불능(impairment)이나 기능제한(dysfunction)에 초점을 두기 때문이다. 동일한 무릎 질환 환자를 검사한다면 물리치료사는 문진을 통해 의심되는 원인을 특정 관절의 가동범위 또는 특정 근육 의 유연성, 근력 및 근지구력, 그리고 운동조절 및 협응 능력의 불능 (impairment)이나 밀기, 당기기, 서기, 걷기 등 일상생활 동작의 기능제 한(dysfunction)에 초점을 두고 검사하게 된다. 그리고 핵심고리(key link)가 되는 부분을 우선으로 중재하게 된다. 하지만 아쉽게도 이런 일련의 과정이나 치료방법이 의학만큼 체계화되어 있지 않다.

이와 같은 문제점과 병리(pathology)가 진단(diagnosis)의 중심이 되 는 의학 분야의 차이를 보완하기 위해 The american physical therapy association (APTA)에서 'guide to physical therapist practice'을 발표하였 고 물리치료사를 위한 진단의 필요성을 강조했다. ' guide to physical therapist practice'는 파트 1. 환자/고객관리(patient/client management) 과 파트 2. 선호되는 치료형태(preferred practice pattern)로 구분되어 있다. 파트 1은 환자/고객관리(patient/client management)를 위한 성분 을 검진(examination), 평가(evaluation), 진단(diagnosis), 예후(prognosis), 중재(intervention)의 다섯 요소로 구분한다. 이는 세계물리치료 사연맹(WCPT)의 분류와도 일치한다.9 SOAP노트의 주관적 평가, 객 관적 평가, 사정(assessment), 치료계획과 내용면에서는 거의 같지만 진단(diagnosis)을 포함한 것은 눈여겨봐야할 부분이다.

\section{2) 평가, 감별진단, 예후의 기초(foundation for evaluation, differential}

\section{diagnosis and prognosis)}

물리치료사의 평가(evaluation)는 검진을 통해 얻은 정보를 이용해 임 상적 판단을 내리는 역동적 과정(dynamic process)으로 이 단계에서 감별진단(differential diagnosis)을 통해 의사진료(consultation) 또는 referral(다른 전문기관으로 안내)을 결정하게 된다. ${ }^{6}$ 물리치료사는 환 자의 응급상황과 병의 징후 또는 약의 부작용 등을 감별해 이상징후 발견 시 전문의나 전문가에게 보내야(refer out) 한다. NPTE에서는 물 리치료사의 응급상황 시 대처능력, 환자 질환의 특정 징후를 스크린 할 수 있는지 여부, 그리고 약 부작용에 대한 이해를 묻는다. ${ }^{6}$ 이는 결 국 물리치료사가 환자의 증상에 대해 위험신호를 감지할 수 있는지, 안전하게 환자에게 적절한 조치를 할 수 있는지 보기 위함이다. 캐더 린 굿맨(Catherine Goodman. MBA, PT)은 그의 저서 'differential diagnosis physical therapist'에서 물리치료사가 감별진단을 할 수 있어야 하는 이유를 다음과 같이 제시하였다. ${ }^{10}$ 오늘날 의료서비스 분야는 점점 복잡해지고, 보다 나은 서비스에 대한 요구 역시 많아지고 있다. 그러므로 물리치료사는 신체계통의 질환(systemic disease)의 위험신 호(red flags)에 대해 반드시 잘 알고 있어야 하고, 특히 조기퇴원환자 의 경우 더욱 주의 깊게 스크린 해야 한다. ${ }^{10}$ 또한 다양한 질환에 동시 에 이환(multiple comorbidities)되어 있는 환자를 중재하므로 근·골격 계나 신경계질환과 같은 기저질환이 있는 환자를 치료할 때 다른 질 환의 가능성이나 약 부작용, 그리고 1차, 2 차 예방을 위한 주의 깊은 스크린이 요구된다. ${ }^{10}$ 경고신호(warning flags)에 대한 정보는 환자가 호소하는 증상이나 치료사의 관찰을 통해 얻을 수 있다. referral(다른 전문기관으로 안내)에 대한 쉬운 예를 들어보자. 요통으로 치료실에 방문한 환자와의 문진 중 요통의 원인이 감염이나 시스템의 이상, 즉 위장질환이나 신장기관의 이상에 의한 연관통이 의심될 때, 물리치 료사는 빠르게 의사결정을 해서 정밀한 검사를 받을 수 있게 도와야 한다. 또 다른 예로 오십견(유착성 견관절낭염) 환자가 잠을 못 이룰 정도의 심한 통증을 호소하거나, 아침에 일어나면 손이 뺏뻣하고 일 상생활을 하는 데 양손 모두 악력의 약화가 두드러진다면 류마티즘 질환을 의심해볼 수 있다. 또한 2년 전 뇌경색 병력이 있는 환자가 최 근 균형 문제를 호소할 때, 발바닥 감각검사 중 상처를 인지하지 못하 고 있고 신체활동이나 식생활, 체중변화 등에 대한 질문을 통해 당뇨 병이 의심된다면 정밀검사를 권해야 한다. ${ }^{10}$ 약 부작용에 대한 예는 다음과 같다. 물리치료실에 방문한 파킨슨병 환자가 최근 짜증이 심 해지거나 성격이 부정적으로 변하고 표정이나 상지의 불수의적인 동 작을 자주 보이는 경우, 치료제인 레보도파(Levodopa)의 부작용 가 능성이 있다. 이와 같은 위험징후 발견 시 물리치료사는 환자나 보호 자에게 상황을 설명하고 의사의 진료를 권유해야 한다." 이런 이유로 의료선진국에 속하는 미국의 대부분 주에서 의사의 referral(다른 전 문기관으로 안내)이나 처방전 없이 환자가 물리치료실에 직접 방문, 물리치료사가 평가와치료(direct access)가 가능하다.

진단(diagnosis)은 평가 과정 중 이나 평가 완료 후 결정된다. 이때 평가 결과에 확진(labeling)을 하게 되며, 이후 진단(diagnosis)은 예후 
(prognosis)와 중재 (intervention)를 위한 분류체계(classification system)로 사용된다. 예후는 중재를 통해 회복 가능한 수준과 이를 위해 소요되는 기간을 의미하고 치료계획(plan of care)이 포함된다. 좋은 예후를 위해서는 환자의 참여 또한 매우 중요하다. 이를 환자 권한부 여(patient empowerment)라고 한다. 환자 권한부여(patient empowerment)는 환자가 자신이 받을 치료방법을 선택할 때 본인의 의사를 표 현하는 등 적극적으로 참여하는 것을 의미한다. ${ }^{12}$ 적극적 참여를 위 해 물리치료사는 치료적 중재방법과 예후에 대해 환자나 가족들에 게 충분히 교육해야 한다. 명확한 치료목표를 설정하는 일 또한 매우 중요하다. 'S.M.A.R.T plan', 즉 구체적이고(specific), 측정 가능하고(measurable), 달성할 수 있으며(achievable), 실현 가능하고(realistic/relevant), 기간이 정해진(time-framed) 목표를 세울 수 있도록 해야 한다. 참여 를 독려하기 위해 재활프로그램의 내용은 환자가 스스로 할 수 있는 목표에서 시작하고 환자가 원하는 부분에 어느 정도 우선권을 주고 훈련을 진행할 수 있다. 물론 이때 환자가 가지는 우선권은 S.M.A.R.T plan에 한한다. ${ }^{13}$ 이와 같이 물리치료사는 자신이 중재하는 범위에서 예후에 대해 환자에게 정확히 이야기해야 하고 그 안에서 환자에게 동기부여 할 방법을 찾아야 한다. 중재(intervention)는 물리치료사가 환자에게 하는 다양한 중재를 의미하고 중재 파트에서 자세히 다루 고 있다.

\section{3) 물리치료 중재(physical therapy intervention)}

물리치료사는 평가한 내용을 토대로 임상결정을 내리고 환자를 중 재하게 된다. NPTE에서는 다양한 질환의 환자에 대해 물리치료사가 적절한 중재를 할 수 있는지에 대해 묻는다. 예를 들어 요추5번(L5) 척 추분리증(spondylolysis)으로 진단받은 환자가 한 시간 이상 서있을 때 허리 통증이 발생한다면 아급성기 물리치료 프로그램에 어떤 운 동치료 방법을 포함시켜야 하는지 묻는다. ${ }^{6}$ 다른 예로 척수손상환자 가 매트에서 휠체어로 이동 훈련을 할 때 이동 방법을 익히는 데 어려 움이 있다면 운동학습 초기에 가장 효과적인 피드백방법과 교육방 법이 무엇인지 묻는다. ${ }^{6}$ 물리치료사가 하는 중재는 직접적인 물리치 료(direct physical therapy) 에만 국한되지 않는다. 'guide to physical therapist practice'는 중재(intervention)를 다음의 세 가지로 구분한다. ${ }^{8}$

\section{(1) 협조(coordination), 의사소통(communication), 서류화(documentation)}

물리치료사는 서비스를 조화롭게 운영하고 치료과정에서 환자와 협 조해 도와가며(coordination), 중재의 반응에 대해 지속적으로 의사소 통(verbal \& nonverbal communication)하고 재검진 여부나 치료 종료 또는 치료 중단을 결정한다. 또한 일련의 과정을 서류화(documentation)함으로써 이를 모든 중재의 기초로 이용한다.
(2) 환자/고객 교육(patient/client-related tnstruction)

물리치료사가 하는 중재 중 최근에 가장 강조되는 것은 환자교육이 다. 예전에는 환자의 재활 마지막 단계에 가정 프로그램(home programs)이 주어졌다. 하지만 최근 여러 연구에서 재활 초기의 급성기 에 환자가 치료시간 외에 하는 집중적인 연습(intensive practice)이 새 로운 기술(skill)을 익히는 데 필수요소임이 밝혀지고 있다. 이는 많은 환자군에 적용되지만 특히 신경학적 손상(neurological damage)을 입 은 환자에게 더욱 중요하다. 물리치료사는 환자가 올바른 방향으로 치료를 진행해 나아갈 수 있도록 물리치료사가 중재하는 범위 안에 서 현재 상태와 예후에 대해 환자에게 안내하고 교육해야한다.

\section{(3) 직접적인 중재(direct interventions)}

'guide to physical therapist practice'는 물리치료사의 직접적인 중재를 치료적 운동(유산소 컨디셔닝 포함), 자가관리와 가정환경 관리를 위 한 기능훈련(일상생활동작과 일상생활의 도구적 활동 포함, 직장에 서의 기능훈련(직업/학교/놀이), 커뮤니티와 레저활동 통합 또는 통 합활동(일상생활의 도구적 활동, 워크 하드닝, 워크 컨디션닝 포함), 도수치료 테크닉(모빌라이제이션/메니플레이션), 장치 및 장비 적용 및 적절한 경우(교정, 보호, 지지 및 보철)의 처방, 기도 청결 테크닉 (airway clearance technique), 피부 재생과 보호 테크닉(integumentary repair and protection techniques), 전기치료 기구(electrotherapeutic modalities), 물리적 기계적 인자 치료기(physical agents and mechanical modalities)로 분류하였다. ${ }^{8} \mathrm{NPTE}$ 에서는 다양한 중재방법에 대해 질 문하는데, 신경계 환자를 위한 신경생리학적 접근법(neurophysiological approaches)에서 보바스, PNF, 운동학습 이론, 브룬스톰 접근법 (brunnstrom approach), 루드 접근법(rood approach)에 대해 묻는다. 예 를 들면, 브룬스톰 접근법은 현재 신경계 질환 환자의 기능평가도구 로 널리 이용되는 FMA (fugl-meyer assessment of physical performance) 에 어떠한 영향을 주었는지 질문한다. ${ }^{6}$

\section{4) 기기 및 물리적 인자치료(equipment \& device, therapeutic modalities)}

NPTE에서는 지팡이, 목발, 보조기 등의 기기와 열전기 치료, 수 치료, 기계적 물리치료에 사용되는 물리적 인자치료에 대해 묻는다. 예를 들어 뇌졸중 환자의 왼쪽 편마비 시 올바른 지팡이 사용법에 대해서 묻거나 발목의 조절이 어려울 경우 어떤 보조기가 필요한지 질문한 다.6 또는 교통사고로 경골 골절(tibia fracture)과 상완 신경총의 견인 손상(traction injury)을 당한 환자의 보행훈련 시 적절한 보행기구가 무엇인지 묻는다. ${ }^{6}$ 물리적 인자치료에서는 초음파 치료에서 열/비열 (thermal/non-thermal) 치료의 차이나 엎드린 자세(prone)에서의 기계 적 견인치료에 대해 묻고 치료 강도나 적용 시간 또한 자세하게 질문 
한다. ${ }^{6}$ 또한 물리적 인자치료에 의해 증상을 호전시키는 생리적 효과 나 교감신경의 활성과 통증 역치의 감소를 억제할 수 있는 기능에 대 해 묻는다. ${ }^{14}$

\section{5) 안전과 보호, 책임, 연구(safety \& protection, professional}

responsibility, research)

$\mathrm{NPTE}$ 는 물리치료사가 환자의 안전을 위해 주의해야 할 점과 환자 보호에 대해 묻는다. 또한 물리치료사는 전문가로서의 책임을 갖고 환자가 해낼 수 있다는 마음을 가지도록 동기를 부여하고 재활이나 치료에 적극적으로 참여하도록 격려하는 역할을 해야 한다. 하지만 그릇된 희망을 불어넣고 격려하기보다는 환자의 상태에 대해 정확히 파악하고 실현 가능한 목표를 제시해 주기를 권한다. 더불어 환자의 고통에 공감하고 존중하는 태도를 요구한다. NPTE에서는 물리치료 사가 다양한 상황에 처한 환자에게 어떻게 동기를 부여할 것인지 묻 는다. ${ }^{6}$

APTA는 'criteria for standards of practice for physical therapy'에서 물 리치료사의 연구역량에 대해 다음과 같이 설명한다.15 "물리치료사는 연구를 통해 얻은 결과를 임상에 적용하고 이를 통해 환자 중재 방법 을 발전시켜야 한다. 임상에 적용하는 연구지식은 반드시 현재에도 통용되는 것이야 한다. 연구대상자들의 권리가 존중되는 동시에 연 구의 진실성도 유지되어야 한다. 물리치료사는 각자의 교육과 경험 그리고 전문분야에 따른 적절한 연구에 참여하고 연구를 임상에 적 용했을 때 그 결과를 동료 치료사나 물리치료학과 학생들, 그리고 다 른 보건전문가나 일반인에게도 알려야 한다." ${ }^{15} \mathrm{NPTE}$ 는 물리치료사 에게 연구방법에 대한 지식과 연구용어에 대해 묻는다. 예를 들어 근 거중심의 의학에서 임상의사결정(dinical decisions)을 위한 최상의 근 거(best source)가 무엇인지 또는 신뢰도나 타당도와 관련된 연구용어 를 묻는다. 근거 중심의 물리치료는 사실 역사가 그리 길지 않다. 물 리치료 분야는1990년대 초까지 임상과 연구가 분리되어 있었다. 물리 치료사들 대부분은 환자에게 질적으로 수준 높은 서비스를 제공해 야 한다고 믿었고 치료를 science based보다는 art based라고 생각했다.

1990년에 홀콤(Holcomb), 셀커(Selker), 루시(Roush)가 실시한 조사 를 보면 물리치료 관련 종사자의 $30 \%$ 가 저널에 저자로 등록된 적이 한 번도 없다고 보고했다. ${ }^{16}$ 이런 수치는 당시 물리치료사들이 연구에 소홀했음을 말해준다. 이는 비슷한 고등교육을 받은 다른 직업군에 비해 낮은 수준이었다. 그러던 중 1994년 월스트리트 저널에 ‘One Bum Knee Meets Five Physical Therapists' 라는 기사가 실린다. 기자는 그녀가 무릎 문제로 다섯 명의 물리치료사를 만났는데 슬개골 연골 연하증의 평가와 치료가 모두 달랐다고 보고했다. 각자 다른 치료계 획을 세웠고 치료비용도 달라졌다. 기자는 치료가 가변적이었고 생물 학적 타당성에 중점을 두었다고 느꼈다. 게다가 제공자가 가장 편하
다고 생각하는 치료를 행하는 것처럼 보였다고 말했다. ${ }^{17}$ 물론 위 이 슈는 물리치료에만 국한되는 것은 아니었다. 맥글린(McGlynn)는 무 작위 전화조사를 통한 연구에서 조사된 환자의 $55 \%$ 만이 권고되는 의료서비스를 받았다고 보고했다. ${ }^{18}$

그 후 의료영역뿐만 아니라 물리치료 분야 역시 근거 중심의 치료 로 패러다임이 바뀌었고 연구와 임상을 더 이상 분리하지 않는다. 하 지만 연구자들은 여전히 임상에서 근거중심의 중재를 하지 않고 있 다고 믿었고, 임상가는 시간 부족과 필수 근거에 대한 접근의 어려움 을 토로했다. 이 문제의 해결을 위해 물리치료 근거 데이터베이스에 대한 요구가 증가했고 APTA의 Hooked on Evidence, 호주 시드니대학 의 FEDro 등이 서비스를 시작했다. 물리치료 근거자료(resources)를 제공하는 physio-pedia, physical therapy haven 등도 등장했다. 위와 같 은 서비스는 물리치료사들이 질적으로도 수준 높은 연구에 접근할 수 있는 다리가 되어주었고 많은 물리치료사들이 근거 중심의 서비 스를 제공하고자 노력하게 되었다. 이와 더불어 물리치료 관련 분야 에 대한 많은 연구가 연구가와 임상가 모두에 의해 진행되고 있고 연 구결과를 임상에 적용하려는 다양한 시도를 하고 있다.

\section{고 찰}

지금까지 미국에서 물리치료사에게 요구하는 최근의 교육과정과 면 허시험인 NPTE에 출제되는 문제의 경향에 대해 알아보았다. 교육과 정과 면허시험을 분석한 결과 둘 다 'guide to physical therapist practice' 를 기초로 하고 있다는 점을 파악할 수 있었다. APTA는 초판'19 'guide to physical therapist practice' 을 발표하였고 이후에 개정판 2.0을 통해 관리(management)와 실습(practice)을 발전시켰고, 3.0 (2016)에서는 WHO의 ICF (International Classification of Functioning, Disability and Health)의 표준화된 언어와 체계(framework)를 받아들이는 등의 다 양한 시도를 하고 있다.820 이와 유사한 사례로 '플렉스너 보고서'를 들 수 있는데, '플렉스너 보고서'에서는 미국의 각 의과대학이 입학 자 격, 등록학생 수, 교수 수, 재원, 실험실 시설, 임상실습 시설 등의 기준 에 따라 기술, 평가되었다. 이러한 기준이 마련되자 미국의 의료수준 은 눈부신 발전을 이루었다. ${ }^{21}$ 'guide to physical therapist practice' 나 '플 렉스너 보고서'같은 사례에서 미루어 볼 때 표준을 마련하는 것이 보 건의료 발전에 도움이 된다는 사실을 알 수 있다.

한 분야의 전문가가 되기 위해서는 자신이 하는 일이 무엇인지 명 확히 알아야 하고, 담당하는 범위를 분명히 해야 한다. WCPT는 생애 를 통해 노화와 손상, 질병, 환경 등으로부터 인간의 최적의 움직임과 기능을 개발하고 유지하며 회복시키기 위한 서비스를 물리치료라 정 의했다. 또 물리치료사의 직업적 의무는 고객에 대한 종합적인 검사 와 평가 및 판단, 진단, 예후, 치료계획 수립을 통해 자신의 전문분야 
범주 내에서 중재 및 치료프로그램을 실행하여 모든 중재 치료결과 를 판단하고 고객들에게 자가관리를 위한 조언을 제공해야 한다고 보고했다.22 물리치료사의 역량 정립을 위한 근거 및 기준을 제시하기 위하여 WCPT에서 제시한 요구사항은 환자 상태에 적합한 포괄적인 검사 평가를 수행할 수 있어야 하며 환자에 대한 임상적 의사결정을 내리기 위해 검사. 평가의 결과를 평가할 수 있어야 하고 진단, 예후, 치료 계획을 수립할 수 있어야 한다. 환자가 다른 전문가의 도움이 필 요하다고 판단될 때, 해당 영역의 전문가에게 의뢰할 수 있어야 하며 중재·치료 프로그램을 실시하고 중재·치료의 결과가 어떤지 판단할 수 있어야 한다. 마지막으로 자가치료 방법을 제시할 줄 알아야 한다 는 내용을 포함하고 있다. ${ }^{22} \mathrm{WCPT}$ 에서는 물리치료사가 스스로 환자 를 진단, 평가, 치료, 예방, 교육을 수행하여 독립적으로 환자를 관리 할 수 있는 역량에 대하여 강조하고 있다.22 완전한 기능 움직임을 강 조하여 물리치료 정의를 "물리치료는 일생 동안 최대한 움직임과 기 능적 능력을 발달. 유지시키며, 보유하기 위한 서비스를 제공해야 하 며 노화과정, 손상 또는 질환으로 인해 움직임과 기능이 힘든 상황에 대한 서비스 역시 제공한다. 물리치료는 또한 증진, 예방, 치료, 재활 영역 내에서 움직임 가능성을 파악하여 최적화시키며, 물리치료사, 환자, 보호자, 환자를 돌보는 의료팀 간의 상호작용, 물리치료사의 전 공 지식과 기술을 사용하여 움직임 가능성을 평가하고 치료목표를 수립하는 과정을 모두 포함한다"라고 내린다.9

본 연구는 이런 세계적인 흐름의 한 사례로 최근에 변화한 미국의 물리치료사 교육과정과 면허시험 경향을 조사해 보았고 그 결과 APTA의 'guide to physical therapist practice'가 변화의 중심에 있다는 사실을 확인 했다. 그리고 'guide to physical therapist practice' 같은 표 준이 교육과정과 면허시험의 토대로 작용할 수 있다는 점을 확인하 였다. 국내 보건의료 환경이 세계 수준으로 발전 하면서 한국 물리치 료 또한 지난 65 년간 많은 발전을 이루어왔다. 하지만 여전히 더 발전 할 수 있는 부분이 있을 것이므로 우리도 국내 물리치료 현실에 맞는 발전을 위한 여러 방안들을 고려해 볼 필요가 있다고 생각한다.

\section{REFERENCES}

1. Lee HS, Lee JH, Kim JH. The comparison of curriculums of physical therapy education department in the World. J Kor Soc Phys Med. 2010;5:151-64.
2. Jae WH. The Influence of professionalism to job satisfaction and job performance of the physical therapist. J Kor Phys Ther. 2015;27:201-06.

3. Goo BO, Park MC, Lee MH, et al. The review on physical therapy curriculum in south korea. J Kor Soc Phys Med. 2010;5:165-72.

4. Song MY, Choi MH, Kim KM, et al The consideration of definition of physical therapy in south korea. J Kor Soc Phys Med. 2010;5:133-41.

5. Kim K, Park ES, Cho YH et al. A study on the development of standard curriculum for physical therapy in korea. J Kor Phys Ther. 2006;18:2332.

6. O'Sullivan SB, Siegelman RP. National physical therapy examination: review \& study guide: International Educational Resources, 2016.

7. Nagi SZ. Some conceptual issues in disability and rehabilitation. Sociolo \& rehabil. 1965:100-13.

8. American Physical Therapy Association. Guide to physical therapist practice 2nd ed. Phys ther. 2001;81:9-746.

9. World Confederation Physical Therapy. WCPT guideline for standards of physical therapy practice. London, 2011.

10. Goodman CC, Heick J, Lazaro RT. Differential diagnosis for physical therapists. 5th ed. St. Louis, Elsevier, 2017.

11. Fruth SJ. Fundamentals of the physical therapy examination: patient interview and tests \& measures. Jones \& Bartlett Publishers, 2013.

12. McGraw-Hill D. Concise dictionary of modern medicine. New York, The McGraw-Hill Companies, Inc, 2002.

13. American Association of Cardiovascular and Pulmonary Rehabilitation. Guidelines for cardia rehabilitation and secondary prevention programs. Champaign, Human Kinetics, 2013.

14. Page MJ, Green S, Mrocki MA, et al. Electrotherapy modalities for rotator cuff disease. Cochrane Databas Syst Rev. 2016;6:Cd012225.

15. American Physical Therapy Association. Criteria for standards of practice for physical therapy, 2014.

16. Holcomb JD, Selker LG, Roush RE. Scholarly productivity: a regional study of physical therapy faculty in schools of allied health. Phys Ther. 1990;70:118-24.

17. Miller L. One bum knee meets five physical therapists. Wall Street Journal. 1994:B1.

18. McGlynn EA, Asch SM, Adams J, et al. The quality of health care delivered to adults in the united states. N Engl J Med. 2003;348:2635-45.

19. American Physical Therapy Association. Guide to physical therapist practice. Phys Ther. 1997;77(11):1160-658.

20. American Physical Therapy Association. Guide to physical therapist practice 3.0. APTA, 2016.

21. Hwang SI. The reform of medical education in the early 20th century america and the fexner report of 1910. Kor J Med Hist. 1994;3(1):1 19.

22. Asia Physical Therapy Association. Discovering physical therapy: What is physical therapy. APTA, 2010. 